\title{
Data Quality Assurance for Supersonic Jet Noise Measurements
}

Clifford A. Brown, Brenda S. Henderson, and James E. Bridges

Glenn Research Center, Cleveland, Ohio 


\section{NASA STI Program . . . in Profile}

Since its founding, NASA has been dedicated to the advancement of aeronautics and space science. The NASA Scientific and Technical Information (STI) program plays a key part in helping NASA maintain this important role.

The NASA STI Program operates under the auspices of the Agency Chief Information Officer. It collects, organizes, provides for archiving, and disseminates NASA's STI. The NASA STI program provides access to the NASA Aeronautics and Space Database and its public interface, the NASA Technical Reports Server, thus providing one of the largest collections of aeronautical and space science STI in the world. Results are published in both non-NASA channels and by NASA in the NASA STI Report Series, which includes the following report types:

- TECHNICAL PUBLICATION. Reports of completed research or a major significant phase of research that present the results of NASA programs and include extensive data or theoretical analysis. Includes compilations of significant scientific and technical data and information deemed to be of continuing reference value. NASA counterpart of peer-reviewed formal professional papers but has less stringent limitations on manuscript length and extent of graphic presentations.

- TECHNICAL MEMORANDUM. Scientific and technical findings that are preliminary or of specialized interest, e.g., quick release reports, working papers, and bibliographies that contain minimal annotation. Does not contain extensive analysis.

- CONTRACTOR REPORT. Scientific and technical findings by NASA-sponsored contractors and grantees.
- CONFERENCE PUBLICATION. Collected papers from scientific and technical conferences, symposia, seminars, or other meetings sponsored or cosponsored by NASA.

- SPECIAL PUBLICATION. Scientific, technical, or historical information from NASA programs, projects, and missions, often concerned with subjects having substantial public interest.

- TECHNICAL TRANSLATION. Englishlanguage translations of foreign scientific and technical material pertinent to NASA's mission.

Specialized services also include creating custom thesauri, building customized databases, organizing and publishing research results.

For more information about the NASA STI program, see the following:

- Access the NASA STI program home page at http://www.sti.nasa.gov

- E-mail your question via the Internet to help@ sti.nasa.gov

- Fax your question to the NASA STI Help Desk at 443-757-5803

- Telephone the NASA STI Help Desk at 443-757-5802

- Write to: NASA Center for AeroSpace Information (CASI) 7115 Standard Drive Hanover, MD 21076-1320 


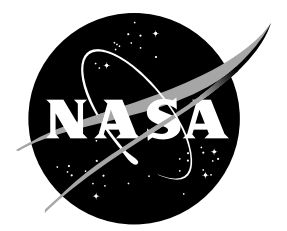

\section{Data Quality Assurance for Supersonic Jet Noise Measurements}

Clifford A. Brown, Brenda S. Henderson, and James E. Bridges

Glenn Research Center, Cleveland, Ohio

Prepared for the

Turbo Expo 2010

sponsored by the American Society of Mechanical Engineers (ASME)

Glasgow, Scotland, United Kingdom, June 14-18, 2010

National Aeronautics and

Space Administration

Glenn Research Center

Cleveland, Ohio 44135 


\section{Acknowledgments}

This work was supported by the NASA Fundamental Aeronautics Program, Supersonics Project.

Trade names and trademarks are used in this report for identification only. Their usage does not constitute an official endorsement, either expressed or implied, by the National Aeronautics and Space Administration.

This work was sponsored by the Fundamental Aeronautics Program at the NASA Glenn Research Center.

Level of Review: This material has been technically reviewed by technical management.

Available from

NASA Center for Aerospace Information 7115 Standard Drive

Hanover, MD 21076-1320
National Technical Information Service 5301 Shawnee Road Alexandria, VA 22312

Available electronically at http://gltrs.grc.nasa.gov 


\title{
Data Quality Assurance for Supersonic Jet Noise Measurements
}

\author{
Clifford A. Brown, Brenda S. Henderson, and James E. Bridges \\ National Aeronautics and Space Administration \\ Glenn Research Center \\ Cleveland, Ohio 44135
}

\begin{abstract}
The noise created by a supersonic aircraft is a primary concern in the design of future high-speed planes. The jet noise reduction technologies required on these aircraft will be developed using scale-models mounted to experimental jet rigs designed to simulate the exhaust gases from a full-scale jet engine. The jet noise data collected in these experiments must accurately predict the noise levels produced by the fullscale hardware in order to be a useful development tool. A methodology has been adopted at the NASA Glenn Research Center's Aero-Acoustic Propulsion Laboratory to insure the quality of the supersonic jet noise data acquired from the facility's High Flow Jet Exit Rig so that it can be used to develop future nozzle technologies that reduce supersonic jet noise. The methodology relies on mitigating extraneous noise sources, examining the impact of measurement location on the acoustic results, and investigating the facility independence of the measurements. The methodology is documented here as a basis for validating future improvements and its limitations are noted so that they do not affect the data analysis. Maintaining a high quality jet noise laboratory is an ongoing process. By carefully examining the data produced and continually following this methodology, data quality can be maintained and improved over time.
\end{abstract}

\section{Nomenclature}

AAPL Aero-Acoustic Propulsion Laboratory

$\mathrm{D}_{\mathrm{j}} \quad$ jet diameter

HFJER High-Flow Jet Exit Rig

$\mathrm{M}_{\mathrm{fj}} \quad$ flight stream Mach number

$\mathrm{NPR}_{\mathrm{c}} \quad$ nozzle pressure ratio, core stream

$\mathrm{NPR}_{\mathrm{f}}$ nozzle pressure ratio, fan stream

$\mathrm{NTR}_{\mathrm{c}}$ nozzle temperature ratio, core stream

$\mathrm{NTR}_{\mathrm{f}}$ nozzle temperature ratio, fan stream

RFM reticulated foam metal

$\mathrm{U}_{\mathrm{j}} \quad$ jet exit velocity

$\mathrm{U}_{\mathrm{rfm}} \quad$ velocity at downstream face of RFM

\section{Introduction}

The noise created by a supersonic aircraft is a primary concern in the development of future high-speed planes. While the sonic boom is the biggest noise problem during cruise, the engine remains the largest source of noise at takeoff and landing. Historically, the most significant engine noise reductions on subsonic aircraft have been the result of increasing the bypass ratio (BPR), which also improves fuel efficiency. As the BPR increases, the overall jet velocity and the generated jet noise decrease. Unlike their subsonic counterparts, however, the high thrust and low drag requirements of supersonic flight limit the bypass ratio on a supersonic aircraft. Reducing the engine noise created by a supersonic aircraft will require developing new and existing technologies that mitigate the noise sources in the jet or shield the jet noise from the observer. These technologies will typically be tested and verified using high-quality scale-model experiments.

Technology for a complex system, such as a jet engine, typically starts life in a simplified form and is tested in a numerical simulation or a small-scale experiment. The concepts that show promise advance to ever more realistic model-scale experiments before finally being deployed on an actual product. Under this paradigm, it is critical that the model-scale experiment appropriately represents the full-scale system. A methodology has been adopted at the NASA Glenn Research Center's Aero-Acoustic Propulsion Laboratory (AAPL) to insure the quality of the supersonic jet noise data acquired in scale-model experiments using the facilitiy's High Flow Jet Exit Rig (HFJER). This methodology has been developed to provide confidence that the model-scale results accurately reflect the acoustic performance of a noise reduction technology on an actual aircraft engine.

There are many potential sources of contamination, error or uncertainty in a jet noise measurement. High ambient noise levels, control of the jet exit condition, and data acquisition and processing are just a few common examples. It is important to look at each source and evaluate its potential impact for a given flight regime. Subsonic jets, for example, produce lower levels of jet noise than supersonic jets and, therefore, are more susceptible to corruption by background noise. Conversely, the high noise levels produced by a supersonic jet open the potential for the non-linear propagation of sound, a real effect that is difficult to account for and, therefore, can introduce uncertainty into the measurement when limitations in the data processing capabilities are considered. Both subsonic and supersonic jet noise measurements may be contaminated by noise originating from within the jet rig, which can increase in amplitude as the flow rate and pressure in the rig increase.

NASA's Fundamental Aeronautics Program, Supersonics Project is tasked with developing the fundamental technologies for the future of supersonic flight. Maintaining jet rig facilities capable of producing quality jet noise 
measurements is a critical to developing these technologies. Previous work at NASA GRC has systematically focused on insuring the acoustic data quality measured from a singlestream subsonic jet (Refs. 1 and 2). A similar systematic approach is now used to improve the acoustic data quality measured from a dual stream supersonic jet with and without a flight stream. Problems common to all jet noise measurements, such as rig noise and data repeatability, are considered under this approach, while issues particular to supersonic jet noise, such as broadband shock associated noise and non-linear propagation effects, are given special consideration.

\section{Methodology}

A systematic approach to improving the quality of supersonic jet noise data has been applied using data acquired from the HFJER. The methodology starts by defining three primary sources of noise in a jet noise experiment: jet noise, background noise, and rig noise. Jet noise, which may be subdivided into components such as mixing noise and broadband shock associated noise, is generated by the flow features in the high-speed jet plume. Background noise encompasses all noise sources present in the test cell when the jet is not running, including any tunnel or free-jet flow used to simulate the effect of forward flight. All remaining noise sources are characterized as rig noise and are associated with the operation of the HFJER.

Efforts to improve jet noise must start by identifying and mitigating any background noise source which has sufficient amplitude to impact the jet noise data. The background noise levels are measured before (and often after) the jet noise data are recorded. The background noise and jet noise may then be compared, on a frequency by frequency basis, to locate possible background noise contamination in the jet noise data. If the background noise is within $3 \mathrm{~dB}$ of the jet noise at any frequency, the data at this frequency are considered tainted and removed from the jet noise spectrum. Depending on its source and location, it may or may not be possible to reduce a background noise source that is consistently problematic. For example, the installation of a sound absorbing lining and sand bagging of access doors has reduced the background noise associated with the free jet that surrounds the HFJER. However, reducing the noise generated by the electrical substation located near the AAPL has been deemed impractical.

After the background noise is identified, noise originating inside the jet rig is addressed. Common sources of rig noise, such as flow noise radiating through a pipe or noise caused by flow through a choke plate, typically increase as the jet noise increases making rig noise difficult to isolate. It is possible, however, to use the scaling properties of the jet noise itself to isolate the rig noise.

Jet mixing noise is created when the high-speed jet exhaust leaves the nozzle and mixes with the ambient air surrounding the jet. The level of mixing noise produced depends on the strength of the shear layer between the jet and the surrounding air, which depends on the velocity difference between the two regions. Experimental and theoretical research has established scaling laws that show how the jet noise changes as this velocity difference changes. Increasing the velocity of the ambient air surrounding the jet while holding the conditions inside the jet rig constant reduces the velocity difference and, therefore, the jet noise. The jet noise reductions can be predicted by the jet noise scaling laws. Rig noise, which is dictated by the flow conditions inside the rig, will remain constant even as the jet mixing noise is reduced, exposing problematic rig noise in the measured spectrum.

Once the background and rig noise sources have been identified, the focus can shift to the jet noise data itself in order to further define the uncertainty in the measurement. There are two important parts to this process. First, the jet control systems used to set and maintain the stated jet exit condition are a potential source of uncertainty. Each temperature or pressure sensor used to determine the jet condition has an uncertainty associated with it. Fluctuations in the supply air pressure and temperature, and the corresponding corrections applied at the control valves, add to the jet condition uncertainty. Second, the instrumentation and data system used to acquire the noise data will introduce some uncertainty into the measurement. Knowledge of the uncertainty in the measurement will lend validity to the measurement and assist in the interpretation of the results.

The jet noise data collected in an experiment should be independent of the jet rig used for the test. In some cases comparing data acquired using two different jet rigs can be used to identify rig noise at one or both facilities. While it is unlikely that the sources of rig noise are the same, both jet rigs have some internal noise, it is unlikely the sources of this noise behave in the same way due differences inherent in the individual jet rigs. This type of comparison test is rarely done because the same model hardware must be tested at the same jet exit conditions on both jet rigs. This is often difficult due to size differences between the jet rigs, particularly at the model mount point, or because of pressure, temperature, or mass flow limitations at one of the two rigs. Where possible, however, these comparison tests can give a good indication of the jet rig independence of data collected at both facilities.

The proposed methodology for improving the quality of a jet noise measurement is a multi-step process. Similar methods have been used at NASA GRC to validate the quality of acoustic data from a single stream jet rig (Refs. 1 and 2) and from a fan model in a wind tunnel (Ref. 3). First, extraneous noise sources are identified and, if possible, removed from the data, leaving only the jet noise. Then, uncertainty in the jet noise measurement is quantified, establishing an estimate of the accuracy of the measurement. Finally, the measurement precision is studied, determining the repeatability of the measurement. Repeatability is often more important than absolute accuracy in scale-model experiments. If carefully 
followed, these procedures should give added validity to the jet noise data produced from any jet rig facility.

\section{Test Setup}

The HFJER, located in the AAPL at GRC (Fig. 1), was used for these experiments. The HFJER is a dual flow jet rig capable of operating in both internally mixed and separate flow nozzle configurations. Air is supplied to the rig by a remote compressor. Jet exit temperatures up to $1425^{\circ} \mathrm{F}$, on the core stream only, can be obtained using a natural gas combustor (fan stream temperature is limited to below $250{ }^{\circ} \mathrm{F}$ ). The maximum flow rate through the jet rig is $20 \mathrm{lbm} / \mathrm{s}$. The HFJER is located inside the Nozzle Acoustic Test Rig (NATR), a 53 in. diameter freejet that provides a simulated flight stream at speeds up to Mach 0.3. The AAPL, a geodesic dome with a radius of $65 \mathrm{ft}$, is lined with sound absorbing wedges to create an anechoic environment at frequencies above $200 \mathrm{~Hz}$. More detail about the AAPL can be found in Reference 4.

A separate flow nozzle system, representative of an exhaust system that might be on a small commercial supersonic aircraft, was used for this test. The system, shown in Figure 2 has a bypass ratio (BPR) of 5 and includes a pylon. The angle of the pylon relative to the sideline microphone array is approximately $122^{\circ}$. The pylon angle relative to the overhead array is approximately $190^{\circ}$ (Fig. 3).

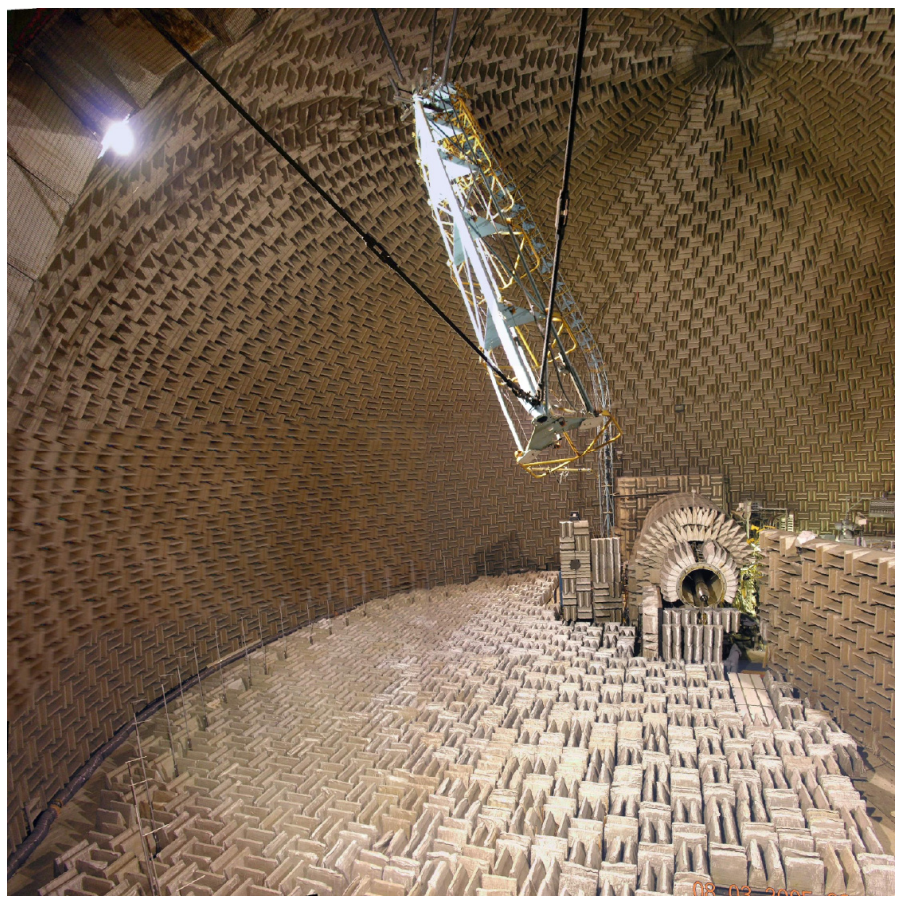

Figure 1.-The AAPL located at GRC houses the HFJER, right center. The blue track across the dome holds the overhead arc microphone array.

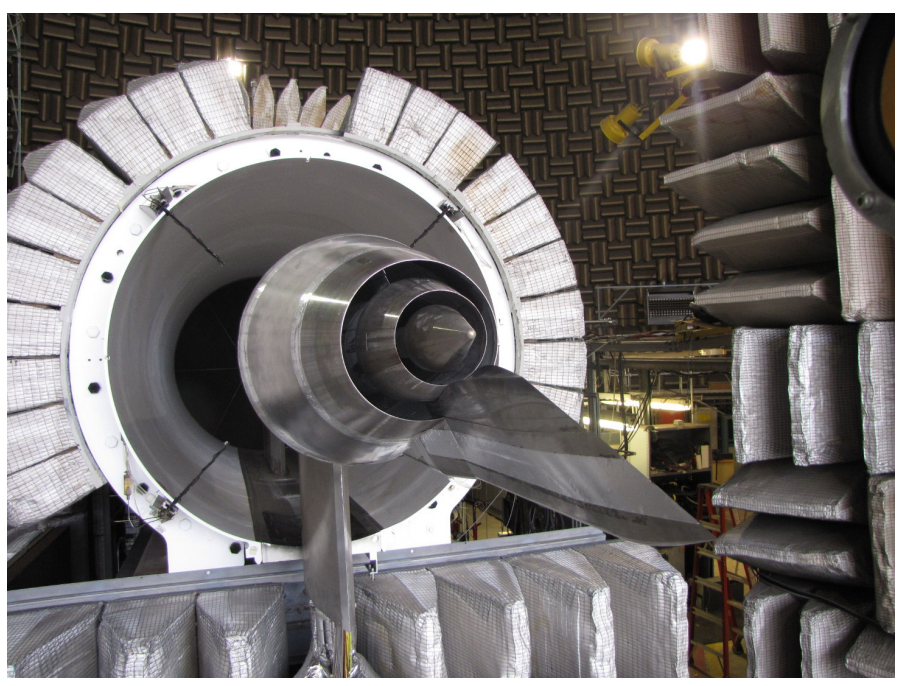

Figure 2.-The separate flow, BPR 5 nozzle system used for the supersonic jet noise quality assessment tests mounted on the HFJER at the AAPL.

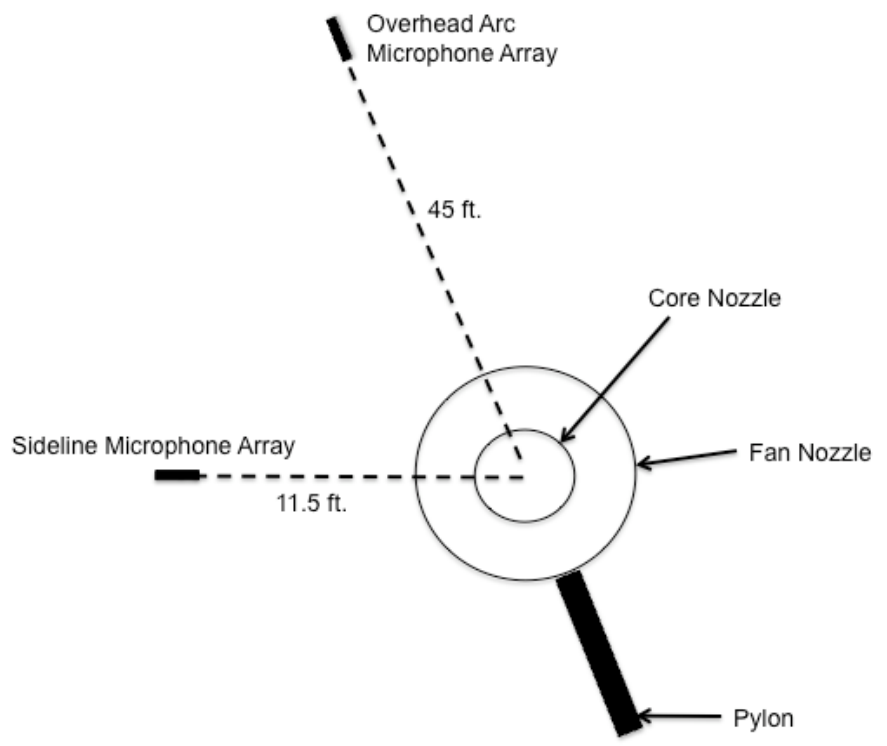

Figure 3.-Schematic drawing of the jet, pylon, and microphone array layout for these tests. The angle of the pylon relative to the sideline microphone array is approximately $122^{\circ}$ and the pylon angle relative to the overhead arc microphone array is approximately $190^{\circ}$. Note that this drawing is not to scale.

Acoustic data were acquired during this test using two separate microphone arrays. The first array, referred to as the overhead arc array, was mounted above the jet, at $22.5^{\circ}$ relative to the top of the model, on a 45 -ft constant radius arc covering polar angles from approximately $45^{\circ}$ to $160^{\circ}$ (Fig. 3). This array uses 24 microphones, placed at $5^{\circ}$ increments, and is the standard far-field acoustic array for the HFJER rig. A second microphone array, referred to as the sideline array, was 
added for these tests. It was placed at the same location relative to the jet as the array at the NASA Langley Research Center's Jet Noise Laboratory (JNL). The sideline array uses 28 microphones and covers polar angles from $45^{\circ}$ to $150^{\circ}$. Bruel \& Kjaer type 4939 1/4 in. microphones were deployed in both arrays.

Data from the two microphone arrays were acquired simultaneously and digitized, at a $200 \mathrm{kHz}$ sample rate, using a DataMAX Instrumentation Recorder from R.C. Electornics. The raw data were filtered with a $90 \mathrm{kHz}$ low pass filter. Once acquired, data were converted from volts to Pascals, using a calibration value measured for each microphone, and transformed to narrowband spectra using a standard FFT routine with a $2^{14}$-point Kaiser window giving a spectral bin width of $12.21 \mathrm{~Hz}$. Background noise was then subtracted from the measured data at each frequency in the spectrum. Next, the data were corrected for the spectral response of the microphone using the calibration supplied for each microphone by Bruel \& Kjaer. The data were also corrected for sound refraction caused by the free jet shear layer. Finally, the data were transformed to a lossless condition and scaled to a measurement distance of $1 \mathrm{ft}$ by correcting for atmospheric attenuation and spherical spreading.

Ambient temperature, pressure, and humidity and all jet conditions are recorded by the facility computer system (ESCORT). Each jet exit condition to be tested is assigned a "setpoint" code and input into the ESCORT computer. Each setpoint is defined by a core nozzle pressure ratio $\left(\mathrm{NPR}_{\mathrm{c}}\right)$, a fan nozzle pressure ratio $\left(\mathrm{NPR}_{\mathrm{f}}\right)$, a core nozzle temperature ratio $\left(\mathrm{NTR}_{\mathrm{c}}\right)$, a fan nozzle temperature ratio, and a flight stream Mach number $\left(\mathrm{M}_{\mathrm{fj}}\right)$. The nozzle pressure ratios are defined using the total pressure in the jet rig upstream of the nozzle and the ambient pressure in the AAPL (NPR = $\left.\mathrm{P}_{\mathrm{t}, \mathrm{j}} / \mathrm{P}_{\mathrm{amb}}\right)$; the nozzle temperature ratios are defined as the jet total temperature relative to the ambient temperature $(\mathrm{NTR}=$ $\mathrm{T}_{\mathrm{t}, \mathrm{j}} / \mathrm{T}_{\mathrm{amb}}$ ). Using this information, ESCORT then provides a real time total error value, updated once per second, which reflects the difference between the actual operating condition and the desired setpoint. The total error value must remain below 0.5 percent during the entire record time for the data to be accepted, setting an upper bound on the measurement error due to the actual jet exit condition. A table showing all the jet conditions tested is shown in the Appendix. Note that the first four digits in the setpoint number indicate the jet condition and the last digit indicates the flight stream Mach number as described in the Appendix.

\section{Separation of Noise Sources}

Any acoustic measurement involving many active systems will include noise from multiple sources. A methodology has been developed to account for the extraneous noise sources that may contaminate the measurements when acquiring jet noise data. The two extraneous noise sources defined in this methodology are background noise and rig noise.

\section{Background Noise}

The first source of noise identified was background noise. Background noise, which includes noise created by the simulated flight stream, is typically more of an issue in subsonic jet noise measurements. Supersonic jets, which produce more jet noise than their subsonic counterparts, should generate jet noise levels well above the background noise level. If background noise is a problem in a supersonic jet noise test, it would first appear at the jet condition with the lowest jet velocity and the highest flight stream Mach number (setpoint 50504, $\mathrm{M}_{\mathrm{fj}}=0.35$ ). At this setpoint, the jet noise is at the lowest level of any point tested while the background noise is the highest level likely to occur during testing because of the high-speed flight stream. Figure 4 shows the background noise level, with a $\mathrm{M}_{\mathrm{fj}}=0.35$ flight stream, relative to the four lowest jet noise conditions tested. As expected, the jet noise is well above the background noise at all setpoints and most frequencies. It is only at the lowest frequencies, below approximately $300 \mathrm{~Hz}$ (the anechoic limit of the AAPL is around $200 \mathrm{~Hz}$ ), that the background noise level comes to within the defined $3 \mathrm{~dB}$ threshold which indicates background noise contamination. The standard acoustic data processing will remove the contaminated jet noise data in this low frequency region and, therefore, additional steps are not required to address the background noise.

\section{Rig Noise}

Once the background noise has been addressed, the rig noise, and its impact on the measured spectrum, must be determined. In this approach, rig noise is broadly defined as any noise that is not background or jet noise. Typically, the compressor, combustor, control valves and the support

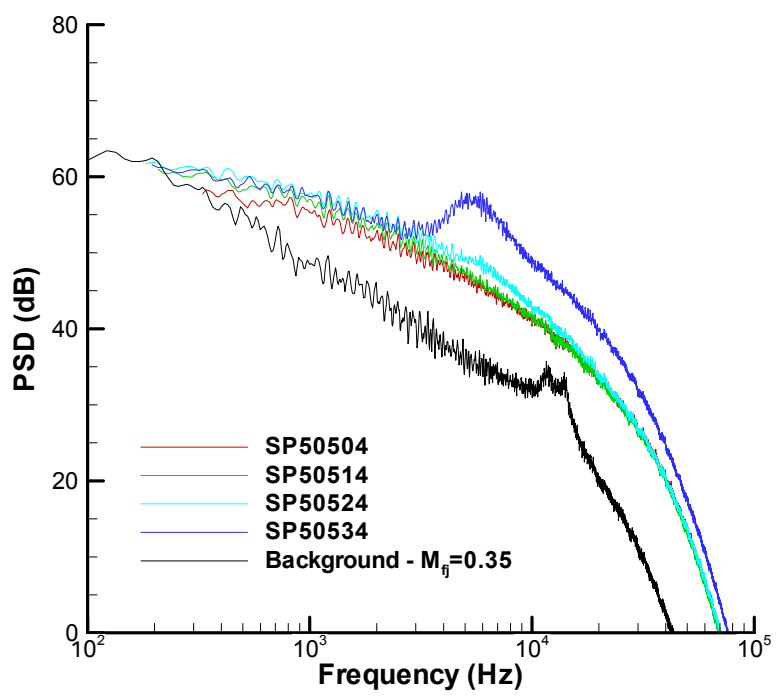

Figure 4.-Background noise measured with a $\mathrm{M}_{\mathrm{fj}}=$ 0.35 flight stream and compared to the lowest noise jet conditions tested. 


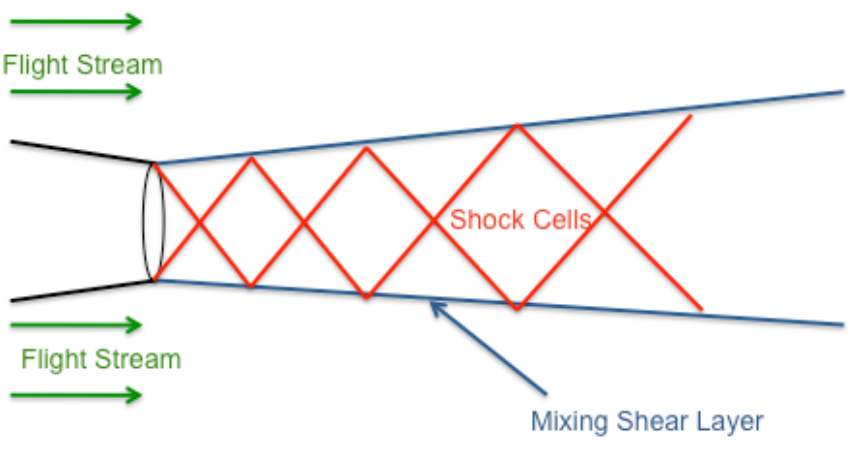

Figure 5.-Schematic showing the structure of a single stream supersonic jet.

structure used to supply high pressure, high temperature air to the test nozzle are the largest sources of rig noise. Since the air flow through the rig is directly related to the jet condition, the rig noise will generally change as the jet exit condition changes. Separating the rig noise from the jet noise, therefore, requires a basic understanding of the physics behind the jet noise sources.

There are two primary noise sources in a supersonic jet: broadband shock associated noise and jet mixing noise. Broadband shock associated noise (BBSN) is created by the interaction between the turbulence in the mixing shear layer and the shock cells in the jet plume (Fig. 5). The peak frequency and amplitude of the BBSN depend on the shape and axial location of the shock cells, which are dictated by the nozzle pressure ratio. While it is important not to confuse BBSN with rig noise, the direct connection between the BBSN and the nozzle pressure ratio makes it difficult to identify any rig noise (which also changes with NPR) by only changing characteristics of the BBSN. The jet mixing noise, however, can be used to determine what impact the rig noise has on the measured spectrum.

The free-shear boundary layer that forms between a highspeed jet and the surrounding fluid is naturally unstable (Fig. 5). As the fluids mix in the jet plume, Kelvin-Helmholtz instability waves are formed. These instability waves grow and decay as the jet develops, governing the formation and destruction of the unsteady turbulent flow structures. These structures are responsible for the creation of the jet mixing noise that characterizes the broadband nature of jet noise. These structures can range in size from the large-scale eddies, on the order of the jet diameter, that transport energy through the jet plume to the small, microscopic eddies that dissipate energy through viscous forces. Experimental and theoretical research has shown that the jet mixing noise may be predicted using the velocity difference between the jet and the surrounding air (Ref. 5). Thus, there are two ways to change the amplitude of the jet mixing noise in an experiment: change the jet exit velocity or change the flight stream velocity. This basic understanding of the physics behind the jet mixing noise source can be used to search for rig noise in a jet noise measurement.

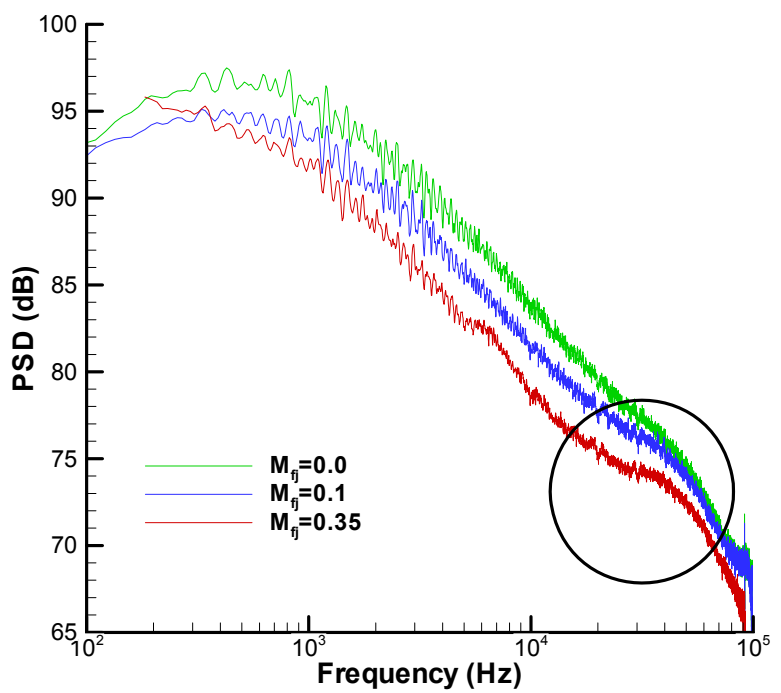

Figure 6.-Separating the rig noise from the jet noise, for setpoints 50500,50501 , and 50504 at the $90^{\circ}$ measurement location, by using three different flight velocities. The circled data shows where the jet mixing noise decreases with the increasing flight stream velocity to reveal the internal rig noise.

A jet rig consists of many pipes, valves, and flow conditioners that are all potential sources of rig noise. Additionally, the characteristics (i.e., amplitude and frequency) of these potential rig noise sources will change as the flow parameters (e.g., pressure, velocity) inside the rig change. Changes to these flow parameters will also change the jet exit condition and, therefore, the jet noise making it difficult to isolate the rig noise from the jet noise. However, if the jet noise changes only because the flight stream velocity changes, then the jet exit condition, internal flow parameters and rig noise will all remain the same. Such a change allows the rig noise to be separated from the jet noise.

Data were acquired at setpoint $50500\left(\mathrm{NPR}_{\mathrm{c}}=1.600, \mathrm{NPR}_{\mathrm{f}}\right.$ $=2.000)$ with no flight stream $\left(\mathrm{M}_{\mathrm{fj}}=0.0\right)$, a Mach 0.1 flight stream $\left(\mathrm{M}_{\mathrm{fj}}=0.1\right)$, and a Mach 0.35 flight stream $\left(\mathrm{M}_{\mathrm{fj}}=0.35\right)$ to demonstrate how the jet noise and rig noise sources may be separated (Fig. 6). A comparison of the spectra from these points shows that the measured noise levels scale with changes to the relative shear layer velocities through the low and midfrequency range. At higher frequencies, however, the data does not scale in the same way. When there is no flight stream $\left(\mathrm{M}_{\mathrm{fj}}=0.0\right)$, the spectrum decreases almost linearly as frequency increases. As the flight stream velocity increases, however, a pronounced 'hump' forms in the spectra indicating the presence of a noise source that does not vary with changes to the velocity difference across the shear layer in the same way jet noise does. This noise source, therefore, is not jet noise but rig noise as defined in this methodology. Note that in these data the rig noise and the jet noise have similar levels, so the resultant amplitude in the affected frequency range is a 
combination of the two sources. If the flight stream velocity were further increased $\left(\mathrm{M}_{\mathrm{fj}}=0.35\right.$ is the limit at this facility) so that there was no velocity difference between the two streams, then the spectra would eventually collapse onto one line representing only the rig noise.

Uncovering rig noise in a jet noise measurement and eliminating it from future measurements are two very different tasks. There are so many potential sources of noise within a jet rig that it can be difficult to isolate the one that is actually causing the problem. The data in Figure 6 show the presence of a noise source in the HFJER rig but little information as to its origin. One approach to identifying the source of this rig noise is to start at the nozzle exit and begin working upstream in search of the rig noise source. In the HFJER, moving upstream from the nozzle exit shows a pair of coarse mesh screens used for flow conditioning, followed by a section of reticulated foam metal (RFM), and then a series of choke plates. Removing the flow conditioning screens did not change the characteristics of the rig noise, therefore the RFM was investigated next. The RFM was added to the rig in part to muffle the noise created by the choke plates farther upstream. Consequently, removing the RFM from the rig would have taken its potential contribution to the rig noise away but it would also reveal choke plate noise that was not previously present in the spectra. Therefore, a small test stand, consisting of a one-inch diameter pipe (fed by a shop air source), a series of choke plates, and a few small disks of RFM, was built to determine the character of RFM and choke plate noise. The results of this sub-scale test showed the RFM as the primary source of the internal rig noise revealed in Figure 6.

The flow inside the HFJER winds its way through the many small passages in a section of RFM before reaching the nozzle exit and produces noise in the process. Data were acquired at several different flow rates using a sub-scale test rig to determine that the noise peaks around $35 \mathrm{kHz}$ and scales approximately as $\mathrm{U}_{\mathrm{rfm}}{ }^{6}$, where $\mathrm{U}_{\mathrm{rfm}}$ is the flow velocity at the downstream face of the RFM section. The RFM associated rig noise, therefore, will increase more slowly than the jet noise (which increases like $\mathrm{U}_{\mathrm{j}}^{8}$ for subsonic and low supersonic jets) and will cease to be a problem for jets above a certain exit velocity. Using this information, the RFM related rig noise could be modeled to determine where and to what extent it affects the jet noise data. The RFM noise data were modeled as:

$$
\text { Rig Noise } \text { RFM }=A_{\text {peak }}-40 \log _{10}\left(f / f_{\text {peak }}\right)^{2}
$$

where $f_{\text {peak }}$ is the frequency where the RFM noise peaks, the factor -40 governs the spectral width of the noise, and the value of $A_{\text {peak }}$ is given by:

$$
A_{\text {peak }}=60 \log _{10}\left(U_{\text {rfm }}\right)-28
$$

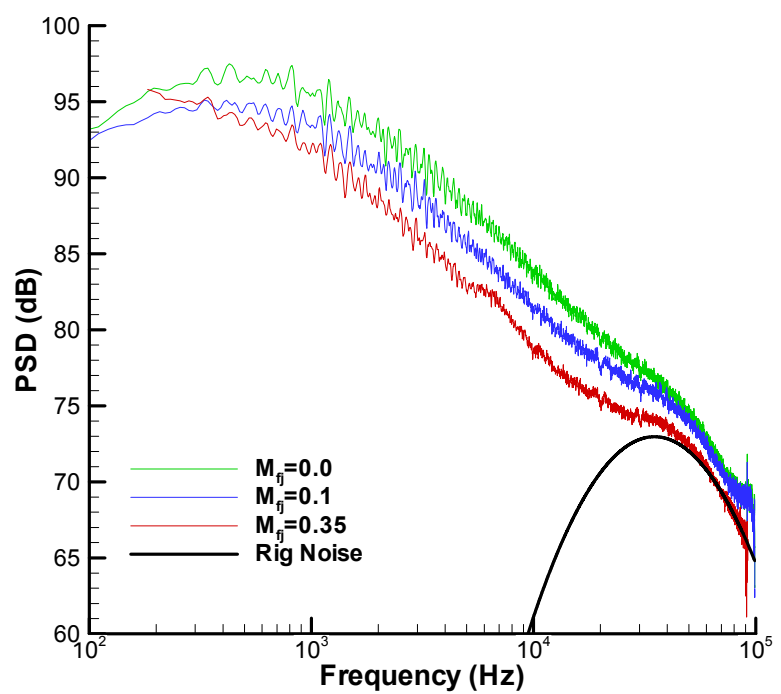

Figure 7.-The effect of rig noise on the spectra measured at $90^{\circ}$ relative to the jet axis for setpoints 50500,50501 , and 50504 , and including the rig noise as determined using a model developed from a series of sub-scale tests.

where the factor -28 is a constant used to adjust the spectra for measurement distance. The modeled RFM related noise is shown in Figure 7 with the data acquired at setpoints 50500 , 50501, and 50504.

The RFM related rig noise definitely has an impact on the spectra measured at the quietest jet noise conditions in the test matrix (Figs. 6 and 7) ${ }^{1}$. Ideally, this rig noise would be removed from the measured data entirely, either by removing or muffling the rig noise source, before completing the remainder of the test matrix. However, this was not practical due to the design of the jet rig, the time constraints, and the goals of the immediate experiments. Therefore, understanding the rig noise characteristics (i.e., frequency range, amplitude, and spectral shape) became a critical part of quality control in these jet noise experiments.

\section{Jet Noise Data Quality}

Following the methodology for data quality assurance, the next step is to examine the jet noise data itself for possible problems. First, the experimental uncertainty in the measurements is quantified. This involves examining the measurement process from the microphone through the data acquisition system. Then, the choice of measurement location is examined. Finally, the repeatability of the jet noise data, both on a single jet rig and between two different jet rigs, is considered. Although not perfect, this systematic approach should give a good understanding of the jet noise data quality and show where improvements may be needed.

\footnotetext{
${ }^{1}$ Modifications to the HFJER to eliminate or greatly reduce the rig noise are underway in preparation for a future series of sub-sonic jet noise test.
} 


\section{Measurement Uncertainty and Precision}

The uncertainty of a measurement is used to assign an error bar, or expected deviation from the true value. There are several sources of uncertainty in the acoustic data acquired in the AAPL. Starting at the microphone and going through the data acquisition system, analysis has shown that the primary sources of uncertainty (Table 1) are the microphone calibrator and the correction for the spectral response of each individual microphone (Refs. 2 and 6). A Bruel \& Kjaer type 4220 pistonphone, with a manufacturer specified uncertainty of $0.15 \mathrm{~dB}$, is used to determine the volts-to-Pascals pressure conversion factor for each microphone prior to each run. The manufacturer also provides a correction to account for the spectral response of each microphone with an uncertainty of $0.27 \mathrm{~dB}$.

\begin{tabular}{|c|c|c|}
\hline Source & $\begin{array}{c}\mathrm{dB}, \\
\text { Low frequency }\end{array}$ & $\begin{array}{c}\mathrm{dB}, \\
\text { High frequency }\end{array}$ \\
\hline $\begin{array}{l}\text { pistonphone } \\
\text { (B\&K } 4220 \text { spec.) }\end{array}$ & 0.15 & 0.15 \\
\hline $\begin{array}{l}\text { mic. spectral calibration } \\
\text { (B\&K calibration spec.) }\end{array}$ & 0.27 & 0.27 \\
\hline $\begin{array}{l}\text { jet condition } \\
\left(0.5 \% \text { error in } U_{i}\right)\end{array}$ & 0.17 & 0.17 \\
\hline $\begin{array}{l}1 / 3 \text { octave average } \\
\left(\chi^{2,} 1 / 3 \text { octave integration }\right. \\
\text { at } 90 \% \text { confidence })\end{array}$ & 0.33 & 0.01 \\
\hline \multicolumn{3}{|l|}{-OR- } \\
\hline $\begin{array}{l}\text { narrowband average } \\
\left(\chi^{2}, 150 \text { averages at } 90 \%\right. \\
\text { confidence })\end{array}$ & 0.61 & 0.61 \\
\hline Total $-1 / 3$ octave SPL & 0.96 & 0.74 \\
\hline Total - narrowband PSD & 1.24 & 1.24 \\
\hline
\end{tabular}

After the data acquisition system, the next significant source of uncertainty is the ability to define, set, and maintain a specific jet condition. To minimize this uncertainty, a system has been developed to calculate a total error based on the difference between the desired jet setpoint parameters $\left(\mathrm{NPR}_{\mathrm{c}}\right.$, $\mathrm{NPR}_{\mathrm{f}}, \mathrm{NTR}_{\mathrm{c}}, \mathrm{NTR}_{\mathrm{f}}, \mathrm{M}_{\mathrm{fj}}$ ) and the actual values. This total error must remain below 0.5 percent throughout the data acquisition time $(8 \mathrm{sec})$ for a point to be considered valid. Because jet noise scales with the jet velocity, the uncertainty in the noise measured attributed to an error in the jet condition can be estimated by computing the maximum and minimum jet velocities that could occur if the jet parameters varied by 0.5 percent. For example, the uncertainty in the acoustic measurements due to a 0.5 percent variation in jet condition in a single steam jet is estimated to be approximately $0.17 \mathrm{~dB}$.

Finally, the data processing techniques employed add uncertainty to the measurement. Data at each setpoint is acquired for a period of $8 \mathrm{sec}$ at a sample rate of $200 \mathrm{kHz}$ and processed using $2^{14}$ point windows with 50 percent overlap. Any window where the time signal is clipped when digitized is removed. A $\chi^{2}$ analysis considering 150 windows at 90 percent confidence shows that the uncertainty for
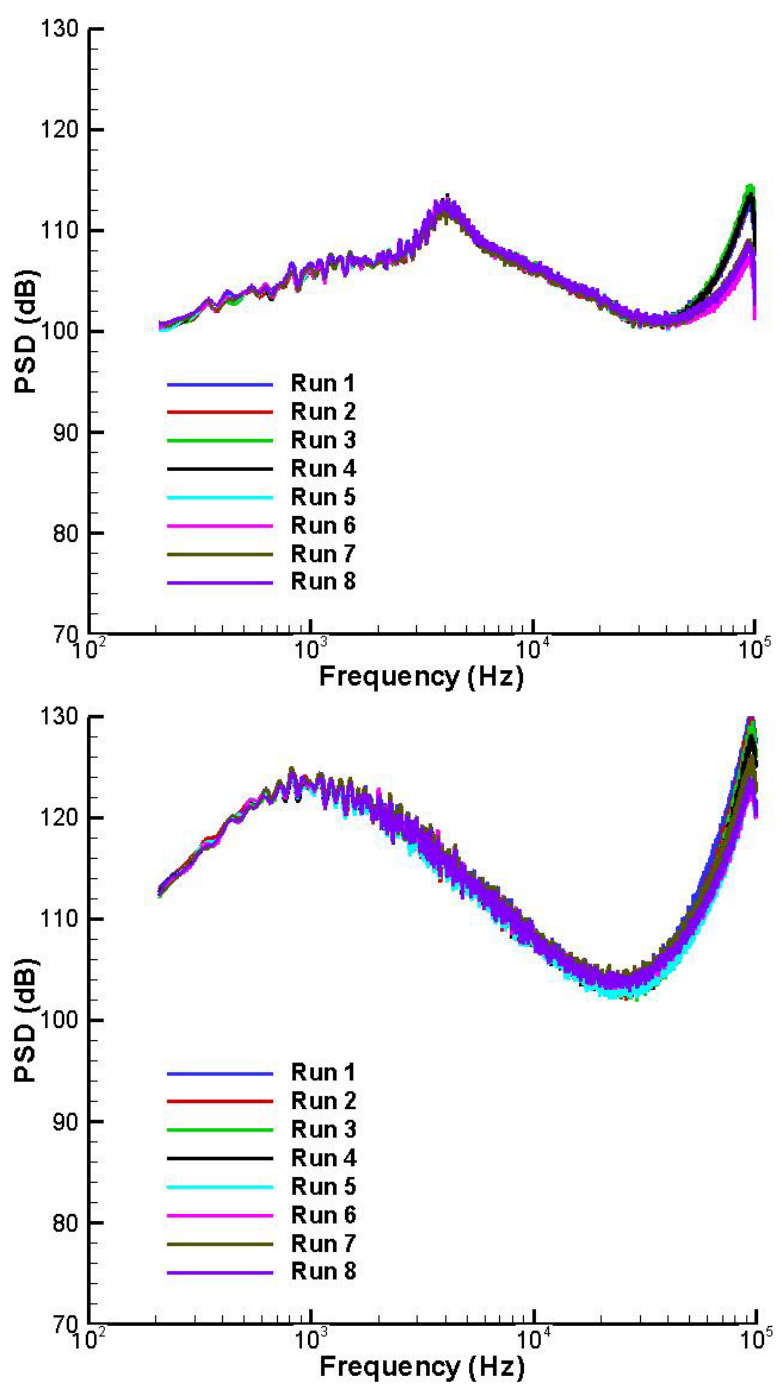

Figure 8.-Precision, or repeatability, of data acquired at $90^{\circ}$ (top) and $150^{\circ}$ (bottom) over several day and repeated model changes from the HFJER using a single stream nozzle configuration, with chevrons, at an ideally expanded jet Mach number of 1.47 . These data are scaled to a $1 \mathrm{ft}$ lossless condition.

narrowband spectral data is $0.61 \mathrm{~dB}$ across the frequency spectrum. Integrating across frequencies to form $1 / 3$ octave spectra reduces the uncertainty to $0.33 \mathrm{~dB}$ at low frequencies and nearly eliminates it at high frequencies. Combining these values yields a total measurement uncertainty of $1.24 \mathrm{~dB}$ for narrowband spectra and less than $1.0 \mathrm{~dB}$ for $1 / 3$ octave spectra.

After the measurement uncertainty is known, the precision of the measurement should be considered. Unlike the uncertainty, however, precision, or repeatability, is not calculated from manufacturer's specifications. Instead, it involves the statistical analysis of repeated experiments using the same model hardware at the same jet conditions. Figure 8 shows a repeat data set acquired over several days and model changes using a single stream nozzle, with chevrons, on the 
HFJER at an ideally expanded jet Mach number of 1.47. These data, which are scaled to a distance of $1 \mathrm{ft}$ from the nozzle exit with atmospheric attenuation removed $(1 \mathrm{ft}$ lossless condition), show that the repeatability over most of the frequency range is approximately $0.5 \mathrm{~dB}$. Only at the highest frequencies, where the atmospheric attenuation correction is the greatest, does the repeatability degrade. The AAPL is an outdoor facility and variations in weather conditions over several days may have caused some of this discrepancy at these high frequencies. Although this analysis is based on data acquired using a single stream jet, it should be noted that both the core and fan streams were used to supply the heated air to the nozzle and, therefore, the repeatability for a dual or separate stream nozzle configuration should be similar.

\section{Measurement Location}

The location of the microphones is an important part of both the test setup and data analysis. There are several factors to consider when choosing a measurement location. Often the physical constraints of the test facility limit the placement of the microphones to locations that are not ideal. In this case, it is important to understand the impact of measurement location on the jet noise data.

Jet noise data are often scaled to represent a measurement at another distance, either to compare with data acquired in another facility or to transform data acquired in a laboratory to a flyover distance. Two assumptions are commonly used in these transformations. First, an assumption about the source location is needed to determine the correct propagation distance of the sound. Second, some assumption regarding the behavior of the sound as it propagates through the atmosphere is needed.

Jet noise is produced by many sources distributed throughout the plume. In general, the higher frequency sources are located near the nozzle exit while the lower frequency sources are farther downstream. Ideally, the measurement location is sufficiently far away from the jet that this distributed source appears to be a point source to the microphone. In such a case the microphone is considered to be in the geometric far-field of the jet and the nozzle exit can be used to represent the location for all the frequencies in the jet noise spectrum. This simplifies the data processing because an accurate description of the source distribution is not required. If the measurement location is not in the geometric far-field of the jet, some error will be incurred if the nozzle exit is used to represent the entire noise source as the actual distance from the noise source to the microphone will be different than the assumed distance. Previous research has shown that the geometric far-field begins approximately 50 jet diameters $\left(D_{j}\right)$ from a single stream subsonic jet (Ref. 1). Figure 9 shows data measured at several distances from a gas dynamic Mach $\left(\mathrm{V}_{\mathrm{j}} / \mathrm{c}_{\mathrm{j}}\right) 1.5$ jet and scaled to a distance of $1 \mathrm{ft}$, with atmospheric attenuation removed, assuming all noise sources are located at the nozzle exit. The geometric far-field begins at the point
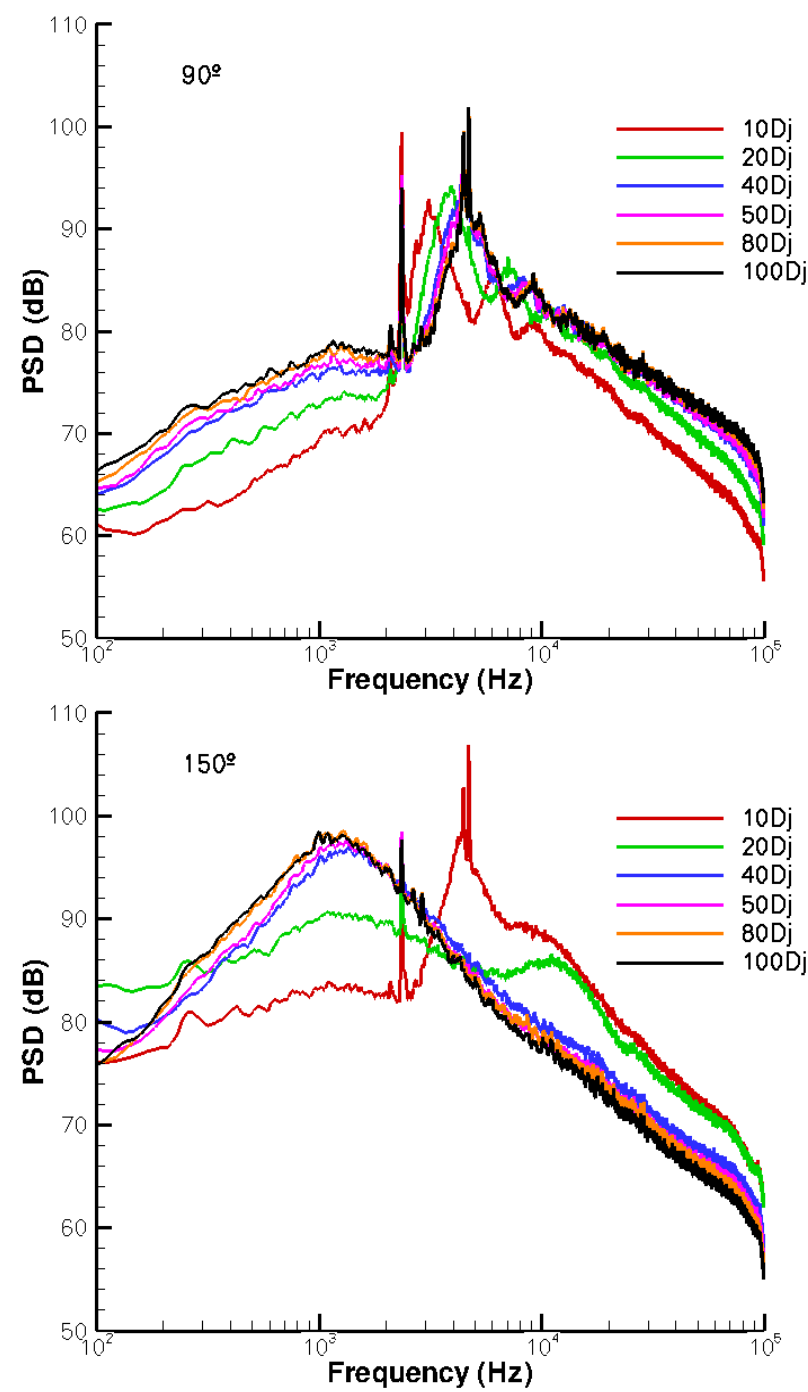

Figure 9.-Spectra measured from a single stream Mach $\left(\mathrm{V}_{\mathrm{j}} / \mathrm{c}_{\mathrm{j}}\right)$ 1.5 jet at $90^{\circ}$ (top) and $150^{\circ}$ (bottom) from the jet axis at several distances from the nozzle exit and scaled to a common distance of $1 \mathrm{ft}$ from the nozzle exit with atmospheric attenuation effects removed (1 ft lossless condition) assuming the measurement is in the geometric far-field.

beyond which the data can be scaled to any common distance with the same result while assuming all frequencies originate at the nozzle exit. These data support using $50 \mathrm{D}_{\mathrm{j}}$ as the minimum geometric far-field measurement distance for supersonic single stream jets which contain both mixing noise and broadband shock noise.

Two microphone arrays were deployed for the HFJER rig validation test: a 45 -ft radius arc array and an 11.5 -ft sideline array. Data were acquired using both arrays and processed to a $1 \mathrm{ft}$ lossless condition assuming that all noise sources are located at the nozzle exit. The sideline array is approximately $20 \mathrm{D}_{\mathrm{j}}$ from the jet at $90^{\circ}$ and $36 \mathrm{D}_{\mathrm{j}}$ from the jet at $150^{\circ}$ (where $D_{\mathrm{j}}$ is the fan nozzle exit diameter). 

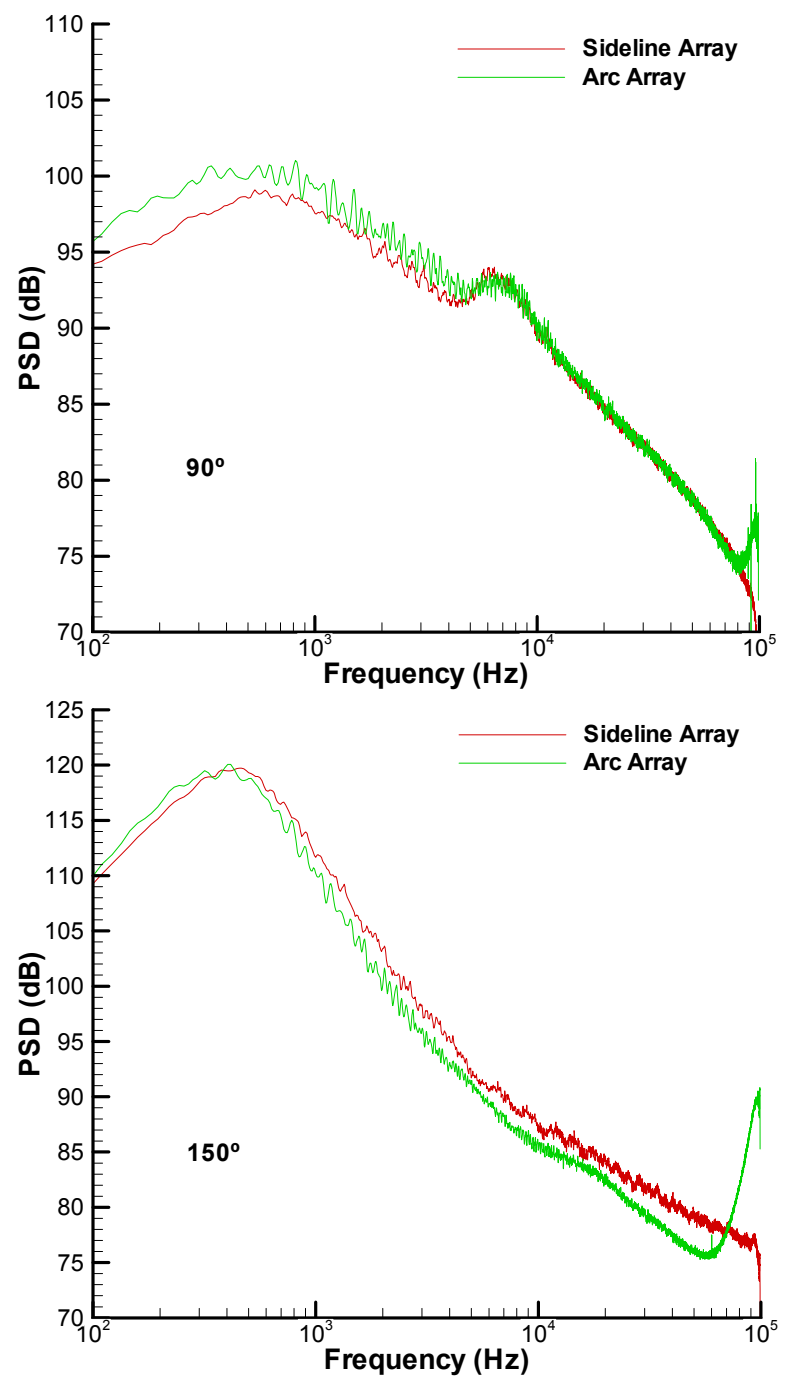

Figure 10.-Spectra showing data acquired at setpoint 50230 using an arc array (45-ft radius) and an 11.5-ft sideline array at $90^{\circ}$ (top) and $150^{\circ}$ (bottom). All data were scaled to a distance of $1 \mathrm{ft}$ and atmospheric attenuation effects removed (1 ft lossless condition) assuming all noise sources were located at the nozzle exit.

The arc array is approximately $80 \mathrm{D}_{\mathrm{j}}$ from the jet at all angles. Based on the above analysis using data collected from a single stream jet, the arc array is in the geometric far-field of the jet while the sideline array is not. Therefore, spectral differences should be expected in the separate flow jet noise data measured using these arrays when scaled to a $1 \mathrm{ft}$ lossless condition. Figure 10 shows data from both arrays acquired simultaneously at setpoint $50230\left(\mathrm{NPR}_{\mathrm{c}}=1.600, \mathrm{NPR}_{\mathrm{f}}=\right.$ 2.200, $\mathrm{NTR}_{\mathrm{c}}=2.310$ ) and scaled to a $1 \mathrm{ft}$ lossless condition. The scaled noise level around the peak frequencies measured by the sideline array at $90^{\circ}$ is $2 \mathrm{~dB}$ lower than that measured by the arc array. At higher frequencies, where the noise source is close to the nozzle exit, data from the two arrays agree. Data measured from the two arrays at the $150^{\circ}$ location also shows a $2 \mathrm{~dB}$ difference, but at frequencies above the peak, cause by a shift toward higher frequencies in the scaled data from the sideline array. Overall, these results are consistent with the previous work and show how factors such as measurement distance should be considered in data analysis and presentation.

The second assumption commonly applied when transforming jet noise data to another distance involves the propagation of sound. Normally, it is assumed that sound propagation is a linear process. If, however, the sound levels are especially high, as might be the case in a supersonic jet, the noise propagation can be a non-linear process, leading to problems associated with accurately scaling the data.

The propagation of sound is a linear process in most cases and data are easily corrected for the distance traveled and the losses incurred due to atmospheric attenuation. As a sound wave travels in space away from its source, the energy spreads in all directions. This spherical spreading reduces the peak amplitude of the sound wave by spreading the same sound energy over a larger area. Spherical spreading over a distance is described for all frequencies by the equation:

$$
\Delta \mathrm{dB}=10 \log _{10}\left(d_{1}^{2} / d_{2}^{2}\right)
$$

where $d_{1}$ and $d_{2}$ are the two distances from the source. Applying only this scaling equation results in the "lossless" propagation of sound where no additional energy is lost to the atmosphere. In reality, some additional energy is lost as the sound wave travels and continually interacts with air molecules and water vapor in its path. Corrections for the atmospheric absorption of sound energy (typically in $\mathrm{dB} / \mathrm{m}$ ) exist and are fairly reliable when the sound propagates linearly (Ref. 7). These corrections are based on the ambient temperature, pressure, and humidity.

When the sound levels become sufficiently high, however, the sound propagation process is no longer linear. The waves steepen as they travel, transferring sound energy from lower to higher frequencies. The distance scaling rules for non-linear sound propagation depend not only on the distance traveled and atmospheric conditions but also on the amplitude and frequency content of the sound. It is important to recognize the impact that applying linear propagation rules to non-linearly propagating sound has on the scaled spectrum.

The nonlinear transfer of energy from low frequencies to high appears to occur in the arc array data presented in Figure 11. The spectrum from the arc array abruptly increases in amplitude around $60 \mathrm{kHz}$ while the data from the sideline array continues to decrease in amplitude. Viswanathan et al., used this method of acquiring data simultaneously at different distances to identify non-linear propagation in data recorded from supersonic jet (Ref. 8). The spectra presented in Figure 11 were transformed to a distance of $1 \mathrm{ft}$ and corrected for atmospheric losses using the standard linear correction method. Data are shown for all of the jet conditions (both cold and hot) set during the test. Each spectra obtained with 

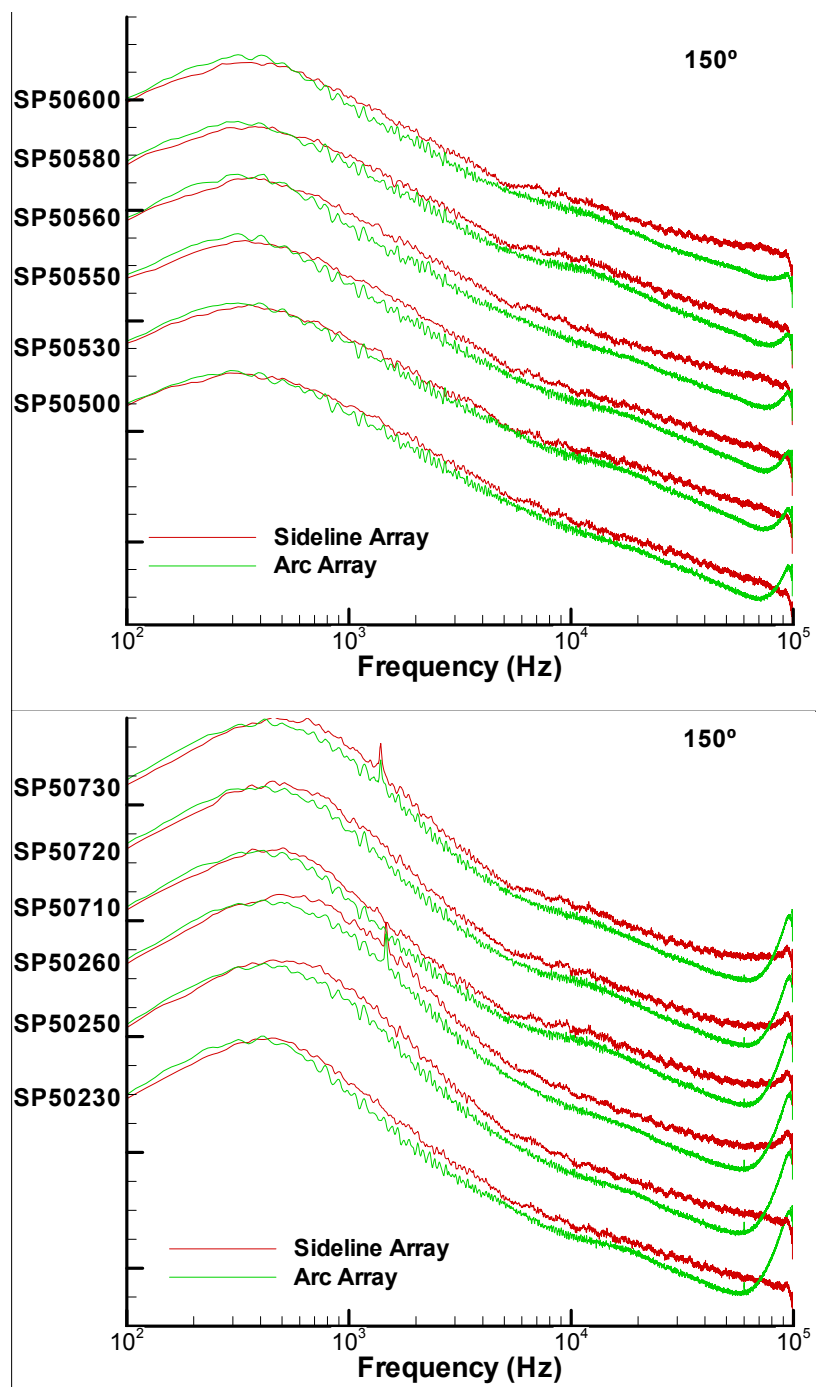

Figure 11.- $\mathrm{PSD}(\mathrm{dB})$ acquired using the sideline array and arc array, at the $150^{\circ}$ location, for all the cold jet conditions (top) and all the hot jet conditions (bottom). Note that the spectra for each setpoint has been shifted to allow all the data to appear on one plot.

the arc array shows some high frequency noise increase, although the effect is much smaller in the data collected at the cold jet conditions. In the previous work Viswanathan et al., found that non-linear propagation only occurred at hot jet conditions (Ref. 8). Additionally, the sound amplitudes measured in their experiments where significantly higher than those measured here which should lead to stronger non-linear sound propagation. More work is needed to confirm whether the increase in high frequency noise shown in Figure 11 is the result of non-linear propagation or some other effect. It is important to note, however, that non-linear propagation effects can impact the spectra measured from supersonic jets and, because of this, measurement location can affect the results even when the data is scaled to a common distance.

\section{Jet Rig Independence}

Model scale tests are designed to prove the capabilities of a new technology without the expense required to build and certify the full-scale hardware. Often, a technology is tested at increasingly larger scale, each time using hardware more representative of the final product. In the process, tests may be conducted on several rigs, possibly in completely different facilities. It is important, therefore, that the data collected be independent of the facility where it is acquired.

No two jet rigs are exactly the same. Each rig has its own strengths and weaknesses. If the jet noise data obtained at one facility is different than that obtained at another, it is difficult to identify which is more accurate. Nevertheless, documenting the differences does provide insight regarding the capabilities of the different facilities.

A nozzle system was recently tested at two NASA laboratories: the Aero-Acoustic Propulsion Laboratory at the GRC and the JNL at the LRC. These tests were conducted using the same model hardware, jet conditions, and measurement locations, in order to document the facility independence of the jet noise data. Figure 12 shows a comparison of the data acquired during these tests (setpoint $50761, \mathrm{NPR}_{\mathrm{c}}=1.800, \mathrm{NPR}_{\mathrm{f}}=2.500, \mathrm{NTR}_{\mathrm{c}}=2.310, \mathrm{M}_{\mathrm{fj}}=$ 0.1 ). A high pass filter was used when acquiring the data at JNL resulting the sharp drop in low frequency sound levels. The peak jet mixing noise, around $1 \mathrm{kHz}$, is increased slightly higher in the AAPL data at the $90^{\circ}$ and $120^{\circ}$ measurement locations but agrees well at the $150^{\circ}$ location. Also, there is a small difference in the high frequency noise at the far upstream and downstream locations. The origin of this discrepancy is currently unknown as the AAPL rig noise is predicted to be well below the jet noise at this setpoint. It is possible these differences are within the ability to repeat the test at the different laboratories and additional tests are required to establish the cross-facility repeatability. The broadband shock associated noise, particularly at the $90^{\circ}$ and $120^{\circ}$ locations, also shows some differences between the two data sets.

BBSN originates in a supersonic jet when the turbulent flow structures, traveling downstream, interact with shock cells in the jet plume. The characteristics of BBSN, therefore, are highly dependent of the location and strength of the shock cells in the jet. In a single stream jet, the shock cell location and structure are driven by the nozzle pressure ratio. In a separate flow jet, however, the situation is more complicated. At setpoint $50761\left(\mathrm{NPR}_{\mathrm{c}}=1.800, \mathrm{NPR}_{\mathrm{f}}=2.500, \mathrm{NTR}_{\mathrm{c}}=\right.$ $2.310, \mathrm{M}_{\mathrm{fj}}=0.1$, Figure 12), the fan stream is supersonic while the core stream is subsonic. Tam et al. studied this scenario and found that there are two mechanisms for generating shocks in a separate flow nozzle (Ref. 9). The first shock cell structure originates at the fan nozzle exit and results from the pressure mismatch between the fan stream and the ambient pressure. The second, and weaker, shock cell structure 


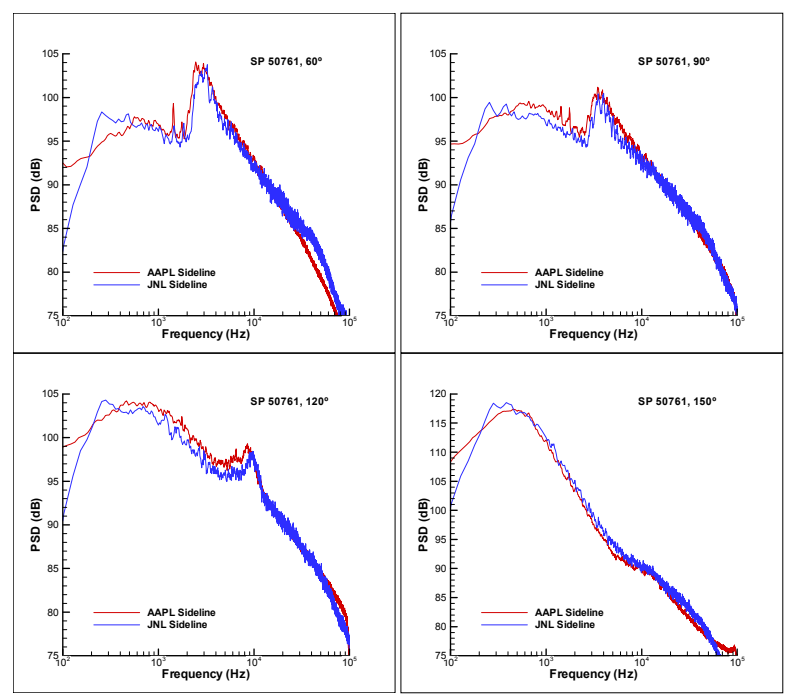

Figure 12.-Spectra acquired at the AAPL and JNL for setpoint 50761 at the $60^{\circ}$ (top, left), $90^{\circ}$ (top, right), $120^{\circ}$ (bottom, left) and $150^{\circ}$ (bottom right) microphone locations. Note that the AAPL sideline array was deployed to match the microphone locations, relative to the jet exit, of the JNL array so all the data were acquired a the same physical locations.

originates at the core nozzle exit plane where the supersonic fan flow turns so that it runs parallel to core flow. The differences observed in the broadband shock associated noise between the JNL and AAPL data (Fig. 12) are most likely attributed to differences in this secondary shock cell structure created by the design of the respective jet rigs. While every effort was made to exactly replicate the test at the two laboratories, an adapter was required to mount the nozzle hardware (originally intended only for the JNL) to the HFJER. This adapter extended the fan stream nozzle exit downstream by approximately 0.176 in., reducing the distance between the fan and core stream exit planes. This shift creates subtle differences in the secondary shock cell structure formed at the two jet rigs which could account for the small differences in BBSN measured at the two facilities.

\section{Conclusions}

A methodology has been developed at the NASA Glenn Research Center's Aero-Acoustic Propulsion Laboratory to assure the quality of the jet noise data measured using the High Flow Jet Exit Rig. Three noise sources were identified in the measured data: background noise, rig noise, and jet noise. Data were acquired to show that the impact of the background noise on the jet noise spectra was minimal. Additional data were acquired to determine the spectral characteristics of the rig noise. A model of the rig noise was developed to examine the affect that the rig noise has on the jet noise spectra. Attention was then focused on evaluating the measured jet noise. This process began by analyzing the uncertainty in the noise measurement from the microphone through the data acquisition system and including data processing techniques. Next, the impact of measurement location was studied by examining spectral differences caused by varying the distance between the jet and the microphone and, in a supersonic jet, the possibility of non-linear sound propagation. Finally, the facility independence of the noise measurements was examined using data acquired at two different NASA laboratories. At each step, the results were documented for future reference. This documentation will be used as a reference when analyzing future data or evaluating future changes to the jet rig design.

Scale-model jet noise experiments are conducted to determine the noise impact of a technology while incurring significantly less expense than otherwise required to build and certify the full-scale hardware. To complete this mission, the data collected in these laboratory experiments must be able to accurately predict the noise characteristics of the full-scale jet. Improving data quality is an ongoing, two part process. First, the problems inherent in any measurement, such as rig noise or data system uncertainty, must be carefully documented so they do not impact the data analysis. Second, the problems identified should be minimized. By carefully examining the data produced and continually following this methodology, data quality will be maintained and even improve over time.

\section{References}

1. Brown, Cliff and Bridges, James, "Small Hot Jet Acoustic Rig Validation," NASA/TM-2006-214234, 2006.

2. Bridges, James and Brown, Clifford, "Validation of the Small Hot Jet Acoustic Rig for Jet Noise Research," AIAA-2005-2846, 2005.

3. Brown, Clifford A. and Schiffer, Nicholas A., "Low Frequency Noise Contamination in Fan Model Testing," GT2008-50850, Proceedings of the ASME Turbo Expo 2008, June 9-13, 2008.

4. Bridges, James, "Measurements of Turbulent Flow Field in Separate Flow Nozzles with Enhanced Mixing Devices - Test Report," NASA/TM-2002-211366, 2002.

5. Viswanathan, K., "Aeroacoustics of Hot Jets," J. Fluid Mech., vol. 516, pp. 39-82, 2004.

6. Bridges, J., Khavaran, A., and Hunter, C.A., "Assessment of Current Jet Noise Prediction Capabilities," AIAA2008-2933, 2008.

7. ANSI S1.26-1995 (R2004), "Method for the Calculation of the Absorption of Sound by the Atmosphere".

8. Viswanathan, K., Alkislar, M.B., and Czech, M.J., "Characteristics of the Shock Noise Component of Jet Noise," AIAA-2008-2835, 2008.

9. Tam, C.K. W., Pastouchenko, N.N., and Viswanathan, K., "Computation of Shock Cell Structure of Dual Stream Jets for Noise Prediction,” AIAA-2008-27, 2008. 



\section{Appendix-Jet Conditions Tested}

The tables below define the jet conditions tested and relate them to a "setpoint" number. The jet exit condition is defined in the first four digits in the setpoint number and the flight stream Mach number is defined by the last digit $\left(\mathrm{M}_{\mathrm{fj}}=0.0\right.$ is $0, \mathrm{M}_{\mathrm{fj}}=0.1$ is 1 , and $\mathrm{M}_{\mathrm{fj}}=0.35$ is 4$)$.

TABLE 2.-THE “COLD” JET CONDITIONS TESTED
WHERE THE CORE STREAM COMBUSTOR
WAS NOT USED SO THAT NTR ${ }_{\mathrm{c}}$ AND
NTR WERE NOT CONTROLLED
[Note the last digit in the setpoint
number indicates the flight stream
Mach number $\left(\mathrm{M}_{\mathrm{fi}}\right)$ ].
\begin{tabular}{|c|c|c|}
\hline Setpoint & NPR $_{\mathrm{c}}$ & NPR $_{\mathrm{f}}$ \\
\hline $50500 / 1 / 4$ & 1.600 & 2.000 \\
\hline $50510 / 1 / 4$ & 1.800 & 2.000 \\
\hline $50520 / 1 / 4$ & 2.000 & 2.000 \\
\hline $50530 / 1 / 4$ & 1.600 & 2.200 \\
\hline $50540 / 1 / 4$ & 1.800 & 2.200 \\
\hline $50550 / 1 / 4$ & 2.000 & 2.200 \\
\hline $50560 / 1 / 4$ & 2.200 & 2.200 \\
\hline $50570 / 1 / 4$ & 1.600 & 2.400 \\
\hline $50580 / 1 / 4$ & 1.800 & 2.400 \\
\hline $50590 / 1 / 4$ & 2.000 & 2.400 \\
\hline $50600 / 1 / 4$ & 2.200 & 2.400 \\
\hline $50610 / 1 / 4$ & 2.400 & 2.400 \\
\hline $50620 / 1 / 4$ & 1.600 & 2.500 \\
\hline $50630 / 1 / 4$ & 1.800 & 2.500 \\
\hline $50640 / 1 / 4$ & 2.000 & 2.500 \\
\hline $50650 / 1 / 4$ & 2.200 & 2.500 \\
\hline $50660 / 1 / 4$ & 2.400 & 2.500 \\
\hline
\end{tabular}

TABLE 3.-THE “HOT” JET CONDITIONS TESTED

[Note that heat was only added to the core stream and the fan stream temperature $\left(\mathrm{NTR}_{\mathrm{f}}\right)$ was not controlled].

[Note the last digit in the setpoint number indicates

\begin{tabular}{|c|c|c|c|} 
the flight stream Mach number $\left.\left(\mathrm{M}_{\mathrm{fj}}\right)\right]$. \\
\hline Setpoint & $\mathrm{NPR}_{\mathrm{c}}$ & $\mathrm{NPR}_{\mathrm{b}}$ & $\begin{array}{c}\mathrm{NTR}_{\mathrm{c}} \\
\mathrm{TT}_{\mathrm{c}} / \mathrm{T}_{\mathrm{amb}}\end{array}$ \\
\hline $50200 / 1 / 4$ & 1.600 & 2.000 & 2.310 \\
\hline $50210 / 1 / 4$ & 1.800 & 2.000 & 2.310 \\
\hline $50220 / 1 / 4$ & 2.000 & 2.000 & 2.310 \\
\hline $50230 / 1 / 4$ & 1.600 & 2.200 & 2.310 \\
\hline $50240 / 1 / 4$ & 1.800 & 2.200 & 2.310 \\
\hline $50250 / 1 / 4$ & 2.000 & 2.200 & 2.310 \\
\hline $50260 / 1 / 4$ & 2.200 & 2.200 & 2.310 \\
\hline $50700 / 1 / 4$ & 1.600 & 2.400 & 2.310 \\
\hline $50710 / 1 / 4$ & 1.800 & 2.400 & 2.310 \\
\hline $50720 / 1 / 4$ & 2.000 & 2.400 & 2.310 \\
\hline $50730 / 1 / 4$ & 2.200 & 2.400 & 2.310 \\
\hline $50740 / 1 / 4$ & 2.400 & 2.400 & 2.310 \\
\hline $50750 / 1 / 4$ & 1.600 & 2.500 & 2.310 \\
\hline $50760 / 1 / 4$ & 1.800 & 2.500 & 2.310 \\
\hline $50770 / 1 / 4$ & 2.000 & 2.500 & 2.310 \\
\hline $50780 / 1 / 4$ & 2.200 & 2.500 & 2.310 \\
\hline $50790 / 1 / 4$ & 2.400 & 2.500 & 2.310 \\
\hline
\end{tabular}




\begin{tabular}{|c|c|c|}
\hline \multicolumn{2}{|c|}{ REPORT DOCUMENTATION PAGE } & $\begin{array}{l}\text { Form Approved } \\
\text { OMB No. 0704-0188 }\end{array}$ \\
\hline \multicolumn{3}{|c|}{ 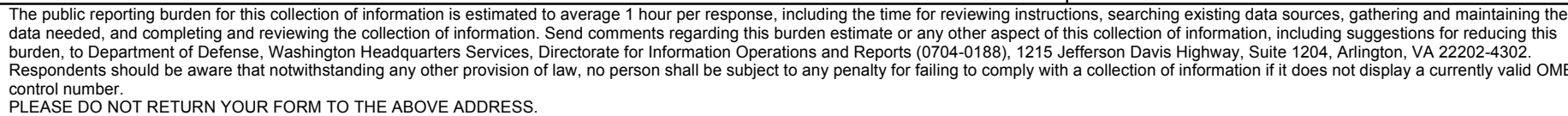 } \\
\hline $\begin{array}{l}\text { 1. REPORT DATE (DD-MM-YYYY) } \\
01-10-2010\end{array}$ & $\begin{array}{l}\text { 2. REPORT TYPE } \\
\text { Technical Memorandum }\end{array}$ & 3. DATES COVERED (From - To) \\
\hline \multirow{3}{*}{\multicolumn{2}{|c|}{$\begin{array}{l}\text { 4. TITLE AND SUBTITLE } \\
\text { Data Quality Assurance for Supersonic Jet Noise Measurements }\end{array}$}} & 5a. CONTRACT NUMBER \\
\hline & & 5b. GRANT NUMBER \\
\hline & & 5c. PROGRAM ELEMENT NUMBER \\
\hline \multirow{3}{*}{\multicolumn{2}{|c|}{$\begin{array}{l}\text { 6. AUTHOR(S) } \\
\text { Brown, Clifford, A.; Henderson, Brenda, S.; Bridges, James, E. }\end{array}$}} & 5d. PROJECT NUMBER \\
\hline & & 5e. TASK NUMBER \\
\hline & & $\begin{array}{l}\text { 5f. WORK UNIT NUMBER } \\
\text { WBS } 984754.02 .07 .03 .17 .03\end{array}$ \\
\hline \multicolumn{2}{|c|}{$\begin{array}{l}\text { 7. PERFORMING ORGANIZATION NAME(S) AND ADDRESS(ES) } \\
\text { National Aeronautics and Space Administration } \\
\text { John H. Glenn Research Center at Lewis Field } \\
\text { Cleveland, Ohio 44135-3191 }\end{array}$} & $\begin{array}{l}\text { 8. PERFORMING ORGANIZATION } \\
\text { REPORT NUMBER } \\
\text { E-17392 }\end{array}$ \\
\hline \multirow{2}{*}{\multicolumn{2}{|c|}{$\begin{array}{l}\text { 9. SPONSORING/MONITORING AGENCY NAME(S) AND ADDRESS(ES) } \\
\text { National Aeronautics and Space Administration } \\
\text { Washington, DC 20546-0001 }\end{array}$}} & $\begin{array}{l}\text { 10. SPONSORING/MONITOR'S } \\
\text { ACRONYM(S) } \\
\text { NASA }\end{array}$ \\
\hline & & $\begin{array}{l}\text { 11. SPONSORING/MONITORING } \\
\text { REPORT NUMBER } \\
\text { NASA/TM-2010-216767 }\end{array}$ \\
\hline \multicolumn{3}{|c|}{$\begin{array}{l}\text { 12. DISTRIBUTION/AVAILABILITY STATEMENT } \\
\text { Unclassified-Unlimited } \\
\text { Subject Category: } 71 \\
\text { Available electronically at http://gltrs.grc.nasa.gov } \\
\text { This publication is available from the NASA Center for AeroSpace Information, 443-757-5802 }\end{array}$} \\
\hline
\end{tabular}

\section{SUPPLEMENTARY NOTES}

\section{ABSTRACT}

The noise created by a supersonic aircraft is a primary concern in the design of future high-speed planes. The jet noise reduction technologies required on these aircraft will be developed using scale-models mounted to experimental jet rigs designed to simulate the exhaust gases from a full-scale jet engine. The jet noise data collected in these experiments must accurately predict the noise levels produced by the full-scale hardware in order to be a useful development tool. A methodology has been adopted at the NASA Glenn Research Center's Aero-Acoustic Propulsion Laboratory to insure the quality of the supersonic jet noise data acquired from the facility's High Flow Jet Exit Rig so that it can be used to develop future nozzle technologies that reduce supersonic jet noise. The methodology relies on mitigating extraneous noise sources, examining the impact of measurement location on the acoustic results, and investigating the facility independence of the measurements. The methodology is documented here as a basis for validating future improvements and its limitations are noted so that they do not affect the data analysis. Maintaining a high quality jet noise laboratory is an ongoing process. By carefully examining the data produced and continually following this methodology, data quality can be maintained and improved over time.

\section{SUBJECT TERMS}

Aerodynamic noise

\begin{tabular}{|c|c|c|c|c|c|}
\hline \multicolumn{3}{|c|}{ 16. SECURITY CLASSIFICATION OF: } & \multirow{2}{*}{$\begin{array}{l}\text { 17. LIMITATION OF } \\
\text { ABSTRACT } \\
\text { UU }\end{array}$} & \multirow{2}{*}{$\begin{array}{l}\text { 18. NUMBER } \\
\text { OF } \\
\text { PAGES } \\
18\end{array}$} & \multirow{2}{*}{$\begin{array}{l}\text { 19a. NAME OF RESPONSIBLE PERSON } \\
\text { STI Help Desk (email:help@sti.nasa.gov) } \\
\text { 19b. TELEPHONE NUMBER (include area code) } \\
\text { 443-757-5802 }\end{array}$} \\
\hline $\begin{array}{l}\text { a. REPORT } \\
\text { U }\end{array}$ & $\begin{array}{l}\text { b. ABSTRACT } \\
U\end{array}$ & $\begin{array}{l}\text { c. THIS } \\
\text { PAGE } \\
\text { U }\end{array}$ & & & \\
\hline
\end{tabular}



